\title{
Notdienstbefreiung für ältere Kollegen hat Bestand
}

\begin{abstract}
Gerade für ältere Zahnärztinnen und Zahnärzte kann der von Zahnärztekammern und/oder Kassenzahnärztlichen Vereinigungen (KZVen) organisierte Notfalldienst an Feiertagen und über das Wochenende, den Patienten auch ohne schwere Erkrankung in Anspruch nehmen können, zu einer besonderen Belastung führen. Die Möglichkeit der Befreiung vom Notdienst allein aufgrund des Lebensalters besteht in den meisten Kammerbezirken nicht mehr. Die bisher allerdings bestandskräftig von der Teilnahme befreiten Zahnärzte können aber nicht ohne Weiteres zum Notfalldienst herangezogen werden. Dies zeigt eine jüngere Entscheidung des Verwaltungsgerichts (VG) Sigmaringen (Baden-Württemberg).
\end{abstract}

\section{Der Fall}

Der klagende Zahnarzt (Jahrgang 1949) war auf seinen Antrag hin vom zahnärztlichen Notfalldienst befreit. Rechtsgrundlage war $\$ 10$ Abs. 1 der Notfalldienstordnung der KZV BadenWürttemberg in der bis 2013 geltenden Fassung. Demnach waren Zahnärzte, die das 60. Lebensjahr vollendet hatten, auf Antrag vom Notfalldienst zu befreien. Diese Ausnahmeregelung wurde Anfang 2013 ersatzlos gestrichen. Deshalb wurde die Befreiung im Mai 2013 durch die Bezirkszahnärztekammer Tübingen mit sofortiger Wirkung widerrufen.

\section{Die Entscheidung}

$\mathrm{Zu}$ Unrecht, urteilte das VG Sigmaringen mit Urteil vom 01.09.2015 (Az.: 8 K 4124/13) und hob den Bescheid und den Widerspruchsbescheid der beklagten Landeszahnärztekammer auf. Zur Begründung führte das Gericht aus, zwar erlaube $\$ 49$ Verwaltungsverfahrensgesetz des Landes Baden-Württemberg (LVwVfG) grundsätzlich den Widerruf eines bestandskräftigen Verwaltungsaktes, dies allerdings nur unter Voraussetzung einer Gefährdung des öffentlichen Interesses. Eine solche Gefährdung sei trotz der hohen Rechtsgüter, die durch die Organisation des ärztlichen Notdienstes geschützt werden sollten, nicht ersichtlich.

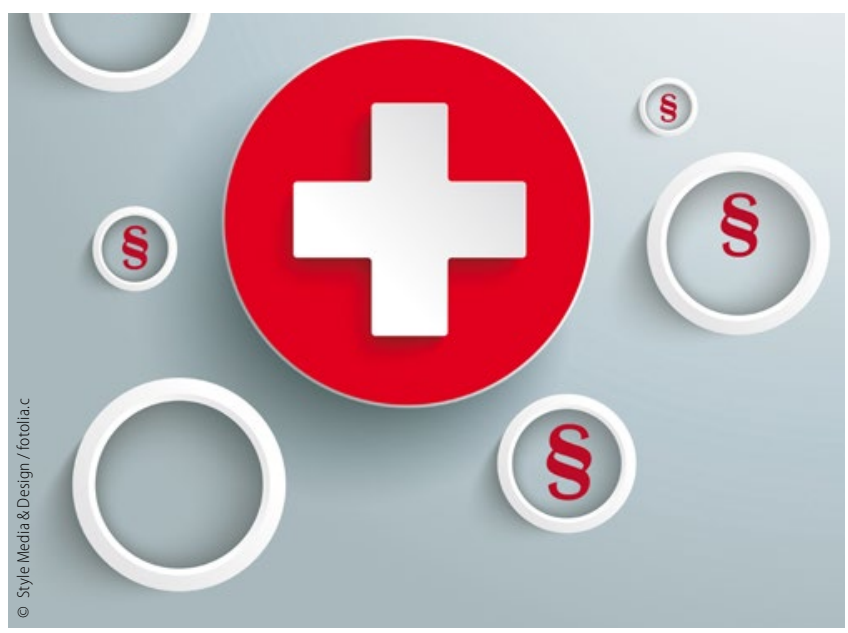

Die Engpässe in einigen Notfalldienstbezirken seien zur Begründung der Gefährdung flächendeckender Notfalldienstversorgung nicht geeignet. Konkret bestand in dem Bezirk, in dem der Kläger niedergelassen ist, kein Mangel an teilnehmenden Zahnärzten.

Die Kammer hatte darüber hinaus argumentiert, sie müsse alle Befreiungen unter dem Gesichtspunkt der Gleichbehandlung widerrufen. Würde sie nur die Befreiungen der Zahnärzte zurückziehen, die in mangelhaft versorgten Gebieten niedergelassen sind, mindere das weiter die Attraktivität der Niederlassung in ländlichen Gebieten. Das überzeugte das Gericht nicht. Eine Ungleichbehandlung läge nur dann vor, wenn Zahnärzte in gut versorgten Gebieten wegen Erreichens der Altersgrenze befreit werden könnten, in ländlichen Gebieten hingegen nicht. Dies sei aber weder in der Vergangenheit noch aktuell die Rechtslage. Die faktische Privilegierung der Zahnärzte in verstädterten Gebieten, die darin bestehe, dass dort schlicht mehr Zahnärzte zur Verfügung stünden und die Heranziehung zum Notdienst deshalb seltener sei, sei durch einen schematischen Widerruf der altersbedingten Befreiung nicht zu ändern. Die Berufung gegen das Urteil wurde zugelassen.

\section{Fazit}

Das Urteil weist in zweierlei Hinsicht über den konkreten Fall hinaus. Zum einen wird deutlich, dass für den Widerruf einer bestehenden Befreiung hohe Hürden gelten. Zum anderen zeigt sich an der Tatsache, dass es die Kammer auf ein Verfahren ankommen ließ, dass sie wie auch die Kammern in anderen Bezirken zukünftig die Befreiungen vom Notfalldienst zunehmend restriktiv handhaben wird.

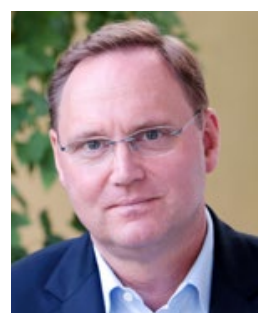

RA Michael Lennartz

www.heilberuferecht.eu 